\title{
HATE SPEECH ON SOCIAL NETWORKS AND TRADITIONAL MEDIA IN REPUBLIC OF N. MACEDONIA
}

\author{
Andon Majhosev, Jadranka Denkova, Shenaj Osmanov \\ Faculty of Law, University “Goce Delchev"- Shtip, N. Macedonia \\ andon.majhosev@ugd.edu.mk, jadranka.denkova@ugd.edu.mk \\ shenaj.osmanov7522@gmail.com
}

Professional Paper

10.5937/jouproman8-27435

\begin{abstract}
The media, especially social networks as a means of mass communication, have an extremely important role in promoting diversity, their respect, tolerance and equality, non-discrimination. Despite this, they often become promoters of hate speech. More recently, in addition to traditional media, hate speech has found a new way to manifest itself through social media, the Internet, whose popularity and widespread use allows certain content to reach the widest audience. The paper addresses hate speech in terms of its presence on social networks and traditional media. The aim is to show the situation in the Republic of Macedonia regarding this issue. Thereby, through the method of descriptive analysis, supported by a series of examples from practice, it is concluded that in the Republic of Macedonia the presence of abuse of media and social networks is noticeable, in order to disrespect diversity, spread prejudice, intolerance and stereotypes.
\end{abstract}

Keywords: hate speech, media, social networks, internet.

\section{Introduction}

The Republic of N. Macedonia is a multiethnic, multiconfesional and multicultural society, whose European perspective and overall development directly depend on the existence of a high degree of social stability, tolerance, nondiscrimination and respect for human rights and freedoms and their equality. The pluralistic and multicultural character of the Macedonian society implies the need to 82 establish new principles and social, ethical and legal rules and norms of behavior, whose function is to develop interculturalism, coordination and interaction, as a prerequisite for harmonious social development. The Republic of Macedonia, created in the rich historical heritage of tolerance, but also on the negative experiences of extreme forms of nationalism, national and religious intolerance, and even armed conflict in 2001, can achieve its European orientation by developing a consistent legal concept. hate speech, as well as consistent application of such a legal concept. This means that the state should ensure respect and protection of human rights and freedoms on the principle of nondiscrimination arising from international law, ie the ratification of conventions in that area. Deepening the problem of intolerance, hatred, hostility and violence on social media towards different social groups and their members requires a new model of conflict resolution, which can cause social instability. 
Lately, hate speech has become more and more pronounced on social networks, where we can notice messages with the content of discrimination, intolerance, hatred, negativity, etc. to a particular social group.

\section{Notion and definition of hate speech and examples of hate speech from the region}

In divided, conflicted and intolerant societies, hate speech is very common and is an important weapon in inciting violence against a particular person or group because of its diversity on the basis of religious, political, national, sexual, linguistic, cultural or other nature. In unstable and divided societies, hate speech causes tense and conflicting situations, which sometimes end in tragic consequences.

The term "hate speech" refers to the use of inappropriate words to promote hate speech, insult, fear, intolerance, discrimination against a particular social group. Some theorists who deal with this issue use the term "hate speech" instead of hate speech, but in essence both terms denote it. There are a number of definitions of hate speech in theory. Although there is no generally accepted definition of hate speech, it is generally considered that hate speech is any speech that aims to insult, humiliate, belittle, intimidate or incite violence or harmful action against a particular person or a group based on their political, racial, social, gender, sexual, or other differences. In the most general sense, the term "hate speech" means verbal or written communication or other form of public expression of an attitude in any form of communication with others (with conclusive actions, gestures, use of symbols, etc.), which contains intent, based on prejudice, to discriminate, harass, provoke a reaction or incite a negative attitude, intolerance, hostility or violence towards individuals or groups of people, based on their racial, or gender, age, ethnicity, nationality, religious beliefs, sexual orientation, disability, occupation, social status, .......... or any other trait. Another definition says, "Hate speech implies propaganda or justification of atrocities, as well as incitement to violence against social groups and their members, based on skin color, ethnicity, gender or sexual orientation." Hate speech also refers to the transmission and transmission of ideas about the superiority or subordination of a social group or its members, as well as the use of symbols that incite hatred and emphasize the superiority or subordination of social groups or their members. $^{2}$

In hate speech, there is no tolerance, respect for the other and his diversity, no matter what the nature of it (diversity). It is aimed at inciting hatred towards those who do not belong to our group or are not with us.

A number of international documents regulate the issue of hate speech $^{3}$.

\footnotetext{
${ }^{1}$ Dimishkova, S. (2008), Freedom of Expression and Democracy, Vecer Press, Skopje p. 36-37

2 Kambovski, V., Lazarova-Trajkovska, M. (2012), Legal Analysis of the Concept of Hate Crime and Hate Speech, OSCE, Skopje;

3 This issue is regulated in the International Convention on the Elimination of All Forms of Racial Discrimination under Art. 4, Recommendation No. R (97) 20 of the Committee of Ministers to Member States on hate speech;
} 
The Council of Europe's Recommendation on Hate Speech states that "hate speech should be understood as covering all forms of expression that spread, specify, promote or justify racial hatred, xenophobia, antiSemitism,.... including intolerance expressed." through aggressive nationalism and ethnocentrism, discrimination and hostility towards minorities, migrants ..."4

Popular theorists say that "hate speech is an expression that denigrates ethnic groups."

\section{Examples of hate speech in} other countries

The question is whether today we can cite examples of this kind of expression (hate speech) from the recent past? The answer is simply YES! An example of hate speech is the 1994 case of RTML (Radio Television Libre des Milles Collines) in Rwanda, when the following message was broadcast on its program: "What are you waiting for? The tombs are empty. Take the swords and cut your enemies to pieces!" The radio's director was sentenced in 2003 by the Rwandan War Crimes Tribunal to life in prison for broadcasting radio shows about the escalation of hatred and genocide perpetrated by the Houthis against members of the Tutsi tribe in the 1994 war.

From the countries in the region, the experience of Bosnia and Herzegovina can be mentioned, during the bloody civil war in the former Yugoslavia 1992-1995. Almost all analysts of this negative phenomenon cite as an example the report of journalist Risto Dzogo, who during the report on the attack on the Sarajevo market Markale on February 5, 1994, which killed

${ }^{4}$ S. Dimishkova, (2008), Freedom of Expression and Democracy, Vecer Press, Skopje, p. 50-51. 84
66 and about 200 wounded, for Serbian television located in Pale, he said: "... Muslims have shelled themselves, wanting to blame the Serbian side ..." He accused Sarajevo authorities of placing the bodies of slain Serbs and shop dolls on the spot just to "hide their own crime" 5 Hate speech is also used in peacetime. A newer example of radical hate speech in Serbia was in 2013 when legitimately elected officials of this country signed the so-called A Brussels agreement on resolving the issue of Kosovo's status and Serbia's European future. Some political structures (parties) have interpreted the agreement between the two sides (the governments of Serbia and Kosovo), mediated by Catherine Ashton, as detrimental to Serbia and the Serbian people in Kosovo, and have since staged protests across Serbia. Thus, at a protest rally in Belgrade, some politicians and religious leaders (Bishop Amfilohije) used hate speech in their speeches, with one politician openly saying that he would meet the fate of Zoran Djindjic. ${ }^{6}$

\section{Legal framework for hate speech in the Republic of Macedonia}

The Republic of Macedonia is a multinational, multicultural and multiconfessional society and it has an appropriate reflection on the legal regulations.

\footnotetext{
${ }^{5}$ Ibid, p. 51-52

${ }^{6}$ Zoran Djindjic was the first prime minister elected in free and democratic elections since the fall of the regime of Slobodan Milosevic in 2000, who was assassinated on March 12, 2004.
} 
The most important legal acts that regulate the issue of hate speech are: the Constitution, the Law on Audio and Audiovisual Media Services, the Law on Media, the Criminal Code, the Constitution of the Republic of N. Macedonia defines the state as democratic, which means guaranteeing a number of political, economic, social and cultural rights. The fundamental value of the Constitution of the Republic of Macedonia is equality and nondiscrimination between people based on equality and respect for diversity. This means that diversity and tolerance are the foundation of Macedonian society and as important democratic values, in addition to the Constitution, are regulated by other laws and code of ethics. Although the multiethnic model of the Macedonian society is regulated by the Constitution of the Republic of Macedonia and a number of laws, in practice we could find frequent use of hate speech against various social groups, especially on a national basis.

The Law on Media prohibits "the publication or dissemination of content in the media to endanger national security, to encourage the violent overthrow of the constitutional order of the Republic of Macedonia, to call for military aggression or armed conflict, to incite or spread discrimination, intolerance or hatred based on race, gender, religion or nationality. ${ }^{7}$

\section{Also, the Law on Audio and Audiovisual}

Media Services prohibits the publication or dissemination of content that incites or disseminates discrimination, intolerance or

\footnotetext{
${ }^{7}$ Article 4 of the Law on Media (Official Gazette of the Republic of Macedonia No. 184/2013 and Official Gazette No. 13/2014)
}

hatred based on race, gender, religion or nationality. ${ }^{8}$

\section{The Criminal Code of the Republic of} Macedonia also provides for imprisonment for causing national, racial and religious hatred, discord and intolerance. The law states that "Anyone who spreads racist and xenophobic writing material, image or other representation of an idea or theory through a computer system in public which helps, promotes or incites hatred, discrimination or violence against any person or group on the basis of sex, race, skin color, gender, marginalized group affiliation, ethnicity, language, citizenship, social origin, religion or belief, other types of beliefs, education, political affiliation, personal or social status, mental or physical disability, age, family or marital status, property status, health status, or any other ground provided by law or a ratified international agreement shall be punishable by one to five years' imprisonment." 9

\section{Self-regulatory acts and bodies in Republic N. Macedonia \\ 4.1 Self-regulatory acts}

The most important self-regulatory acts that regulate and prohibit the use of hate speech in the media are the Code of Ethics for AJM Journalists from 2001 and the Charter for Ethical Election Reporting.

\footnotetext{
8 Article 48 of the Law on Audio and Audiovisual Media Services (Official Gazette of the Republic of Macedonia No. 184/2013 and Official Gazette No. 13/2014)

${ }^{9}$ Article 394-d of the Criminal Code of the Republic of Macedonia (consolidated text)
} 
Hate speech is strictly forbidden in the Code of Ethics of the Journalists of the Republic of Macedonia (Article 10), and in order to respect the principles of the Code, the AJM has established a Council of Honor - a self-regulatory body that takes care of promoting ethical principles, criteria and standards. of professional and responsible journalism.

In 2016, at the initiative of the Council for Media Ethics of Macedonia (SEMM), the largest number of representatives of the most influential media signed a Charter for Ethical Election Reporting. In the Charter, journalists, editors and media executives undertake to respect the basic principles of the journalistic profession, respecting the right of the public to be objectively, truthfully and timely informed and having full responsibility and awareness of the role of the media in the upcoming parliamentary elections. To this end, the Charter defined several principles, including the principle of respect and tolerance, which means respect for the dignity, reputation, rights and personal integrity of individuals in informing the public. The media in its reporting will not use stereotypes, prejudices and underestimation on any grounds and will not use hate speech and inflammatory speech.

\subsection{Self-regulatory bodies in} Republic of N. Macedonia

A) Council of Honor: The Council of Honor is a self-regulatory body of journalists in Macedonia which consists of seven members. Its main task is to take care of and promote the ethical principles, criteria and standards of professional and responsible journalism listed in the Code of 86
Journalists of Macedonia. Article 10 of the Code states that "A journalist shall not incite violence or discrimination on any grounds".

\section{B) The Council for Media Ethics of} Macedonia (CEMM): The Council for Media Ethics in Macedonia (CEMM) is a non-governmental, non-political and nonprofit organization that, on the principle of free will, unites its members to achieve the goals and activities set out in the statute of the organization and the general principles of the mission and vision of SEMM. The Council of Media Ethics of Macedonia (CEMM) was established in 2014. The Council is a self-regulatory body with a mission and goals to promote and protect professional standards and ethics in the media in the Republic of Macedonia. The Council is a body for self-regulation of the media by applying moral sanctions to those who do not comply with professional standards and the Code of Journalism. The Council has the capacity of a legal entity. The members of the Council are: the Assembly, the Board of Directors, the Supervisory Board and the Executive Director.

The Council has an advisory body, the Appeals Commission, which appoints the Board of Directors by consensus, for a term of two years, with the possibility of reelection. The Appeals Commission is composed of seven members elected on the following principle: two representatives of the media owners; two representatives of the journalists proposed by AJM; three representatives of public life who are not professionally related to journalism in the media, but are experts in the field of media, ethics in journalism, media law and other related fields. 
The named Appeals Commission (or Complaints) elects a President and a Deputy from among its members, who are obliged to convene and chair the sessions of the Commission. In 2018, the Complaints Commission of the Council for Media Ethics of Macedonia (CEMM) received more than 121 complaints and appeals, of which 98 decisions were made. The most common complainants are citizens, the media and politicians themselves, and the most common topics are truthfulness and unfair reporting, hate speech and insults and slander. The most common media outlets that have been complained about are the Internet portals with 52 complaints.

\section{Examples of hate speech from the practice in the Republic of $\mathbf{N}$. Macedonia}

\subsection{Case: Gay - marriages}

The topic of same-sex marriage, in our country, is often used as a pretext for homophobic propaganda, followed by open hate speech. For example, the phrase "First they want to get married, then they want to have a child, and finally they want to have the same love?!" are pedophiles. On this topic, a headline appeared: "There is no prosperity of the nation, by adopting children from same-sex partners", and even some more vulgar titles. The most drastic example of inappropriate reporting on this topic is the article in "Vecer" (October 13 and 14, 2012), which as an illustration of the gay population chooses an insect from a pornographic film. Such "illustration" provoked strong negative reactions in the public, and certain comments were titled "The day when Macedonian journalism touched the bottom."
The Honorary Council ${ }^{10}$ of the Association of Journalists of Macedonia (AJM) then assessed that the image was chosen to incite hatred, pointing the finger and portraying homosexuals as pornographic figures, thus degrading and humiliating a social group of people!

\subsection{MTV's Mijak Show}

The show titled "Mijakci" was broadcast on June 5, 2007 as part of the general education program on MTV 1. It is a show in which Peter was given a 30minute space. P., the author of the book "Bloody File", where he says, among other things, about the Gegs (Albanians) that: "generally known in science and defined, that it is a criminogenic nation." In this case, too, the Council of Honor reacted to the show and issued a statement saying that in this case, under the guise of presenting a "scientific study", publicity was given to an undoubtedly chauvinist theory that spreads hatred and ethnic intolerance, which is for the harshest condemnation. “

\subsection{Pray for the Roma not to do gypsy things}

A text with this title appeared in the daily newspaper "Vecer" (June 16, 2008). The article was about the behavior of the Roma in the square in Skopje. This was followed by a series of reactions from the Roma community in Macedonia, and the text was transmitted on social networks by a prominent TV journalist, where it caused controversy by using insulting words among its participants.

10 The Council of Honor is a self-regulatory body established within the Association of Journalists of Macedonia and in relation to cases of hate speech, it undertakes activities on its own initiative to combat this negative phenomenon in the country. 
The aforementioned title later became a favorite among citizens, especially among the young population, which is associated with uncultured and inappropriate behavior in any situation.

\subsection{Hate speech among journalists}

On November 18, 2011 in the show "M. N. The show, which airs on Channel 5, has spread hate speech to certain media outlets and journalists who have worked in other media by labeling them and manifesting open intolerance. In this way, viewers could publicly hear which journalists, according to the host of this TV show, are traitors, mercenaries, police informants and keyboards, which gives the impression that those same journalists are guilty of thinking or acting differently from the host of the show, "the Broadcasting Council said in a statement. Due to the above, the Broadcasting Council of Macedonia fined TV "Kanal 5" with a twoday ban on broadcasting advertisements and teleshopping.

\subsection{Mutual discrediting of} journalists by gender and sexual orientation

Unfortunately, speech, ie hate speech, is also present in the relationship between journalists. The most typical example of discrediting among journalists, ie the editors-in-chief, is the case of the daily newspapers "Vecer" and "Vest". Namely, on January 30, 2013 - in the daily newspaper "Vest" dawned a text entitled "VEST survey" - Which without panties to interview the Prime Minister? ". The editor of the daily newspaper "Vecer" (IT) was also included in the list of journalists (presenters). The next day, January 31,
2013 - the daily newspaper Vecer appeared on the front page with the headline "Are there homosexuals among journalists", illustrated with photos of journalists, including the editor-in-chief of the daily newspaper "Vest", (GM). This distasteful words were followed by violent reactions, and the Association of Journalists of Macedonia (AJM) was among the first to announce its condemnation of the discrediting of journalists by gender and sexual orientation. The daily Vest has withdrawn from the poll, but this will remain the most negative example of the spread of gender-based hatred and sexual orientation among journalists themselves.

\subsection{Hate speech during an}

\section{interview}

A negative example of the use of hate speech in the Republic of Macedonia is the interview of the editor-in-chief of Sitel TV with the leader of the opposition in the Republic of Macedonia who went live, and held in February 2016. During the interview, the leader of the opposition was labeled by the host as a politician who lied like a Turk. The Turkish population in Macedonia is offended by this act. Therefore, the very next day, several associations of Turks in the Republic of Macedonia organized a protest in Skopje against the editor of Sitel TV, demanding a public apology from him. Then the editorin-chief publicly apologized for the mistake made, after which the tensions faded. 


\section{Conclusion}

From the above practical examples we can conclude that social networks (internet) and traditional media in the Republic of Macedonia use hate speech as a way of communication, which is mostly due to impatience on the basis of one of the elements of individuality in a certain social group as well as personal impatience between certain editors and journalists from different media. The use of hate speech in the media is a violation of professional journalistic ethics. Journalists and the media, in the name of their professionalism, should always have respect for the journalistic profession.

The media should encourage and develop communication and exchange of cultural and other values in a multiethnic society. Journalists should avoid disqualifications on ethnic, religious, racial or other grounds - to have a purely professional neutral position. Also, citizens-users of social networks and journalists should keep their opinion to themselves, not to allow the subjective relationship to interfere with the professional, to control their prejudices and feelings, to penetrate the problems of marginal social groups, to strive towards correct and professional attitude, objective presentation of facts, non-manipulation and non-evaluation of the feelings of different groups. Social networks and traditional media, from that aspect, have a huge responsibility to positively influence the audience in terms of diversity and nurturing tolerance and respect for it. Considering the danger of hate speech on the Internet, in order to eliminate hate speech on the Internet, the Council of Europe adopted an Additional Protocol to the Cybercrime
Convention which obliges signatory States to adopt legislative measures to criminalize illegal acts: by distributing and disseminating racist and xenophobic material to the public through a computer system; computer system threat; insult through computer system. The Republic of Macedonia in its penal legislation implements the provisions of the Additional Protocol to the Cybercrime Convention.

\section{Bibliography}

Annual Proceedings of the Faculty of Law, University "Goce Delchev" - Stip, 4 (4). pp. 205 216. ISSN 1857-8713.

Charter for Ethical Election Reporting (2018), SEMM.

Code of Ethics for Journalists of Macedonia (2002), AJM, Skopje.

Constitution of the Republic of Macedonia, 1991.

Dimishkova, S., (2008), Freedom of Expression and Democracy, Vecer Press, Skopje.

Dzamtoska-Zdravkovska, Suzana and Majhosev, Andon and Denkova, Jadranka (2015) Media and hate speech: case study of the Republic of Macedonia. In: Second International Scientific Conference: Social change in the global world, 3-4 Sept 2015, Stip, Macedonia.

International Convention on the Elimination of All Forms of Racial Discrimination discrimination, UN.

Kambovski, V., Lazarova-Trajkovska, M. (2012), Legal Analysis of the Concept of Hate Crime and Hate Speech, OSCE, Skopje.

Law on Audio and Audio Visual Media Services (Official Gazette of RM no. 184/13).

Law on Media (Official Gazette of RM no. 184/13).

Majhosev, Andon (2014), Professional Standards of the Journalism Profession.

Majhosev, Andon (2018), Media Law, Goce Delchev University - Stip. 
(JPMNT) Journal of Process Management - New Technologies, International

Vol. 8, No3, 2020.

Majhosev, Andon and Dzamtoska-Zdravkovska, Suzana and Denkova, Jadranka (2014), An Analysis of the political campaign of political parties during regular presidential andearly parliamentary elections in 2014. In: The 2 nd Internatioanal Conference on "Research and education challenges towards the future", 30-31 May 2014, Faculty of Education Sciences \& Faculty of Social Sciences University of Shkodra "Luigj Gurakuqi".
Majhosev, Andon, (2015), Journalistic Ethics, Goce Delchev University - Stip.

Recommendation No. R (97) 20 of the Committee of Ministers to Member States on hate speech.

Recommendation No. R (97) 21 on the Media and the Promotion of a Culture of Tolerance, Committee of Ministers. 